\title{
Insulin Facilitates Formation of Taurine-Conjugated Bile Acids - Analysis Using Primary Cultured Hepatocytes -
}

\author{
Seitaro OHKUMA, Jun-ichi TAMURA and Kinya KURIYAMA \\ Department of Pharmacology, Kyoto Prefectural University of Medicine, \\ Kawaramachi-Hirokoji, Kamikyo-ku, Kyoto 602, Japan
}

Accepted January 23, 1984

It is well known that various hormones such as insulin, glucagon, catecholamines and glucocorticoids modulate not only metabolisms but also membranous transport of various biological substances in the liver. For investigating the effect of hormones on the membranous transport and metabolism of amino acids, freshly isolated hepatocytes and hepatocytes in primary culture have been found to be suitable (1). Most of the previous studies investigating hormone effects on amino acid transport by hepatocytes, however, used $\alpha$-aminoisobutyric acid (AIB), an artificially synthesized amino acid and non metabolizable in hepatocytes, as a test substance $(1,2)$; and little information is available with regard to the modulating action of hormones on the transport of amino acids which are biosynthesized and metabolized in mammalian organs.

Taurine is known as one of the amino acids biosynthesized and metabolized in hepatocytes (3), and it is used for the formation of taurine-conjugated bile acids in the liver (4-6). The taurine transport in freshly isolated hepatocytes has been reported to be a saturable, sodium- and energy-dependent, and carrier-mediated process (7). The presence of a similar transport system for taurine has been reported in hepatocytes maintained in primary culture $(8,9)$.

In this study, we have investigated the possible modulatory effect of hormones such as insulin and glucagon on the transport of taurine as well as on the formation of taurineconjugated bile acids in freshly isolated hepatocytes and hepatocytes maintained in primary culture.

Adult rat liver parenchymal cells (hepa- tocytes) were isolated from Wistar male rats (weighing 200-300 g), which were maintained under free access to standard laboratory chow and drinking water. Freshly isolated hepatocytes were prepared by a collagenase perfusion technique according to the method of Berry and Friend (10) with a minor modification (7). The hepatocytes obtained were washed three times with ice-cold $\mathrm{Ca}^{2+}$. free Krebs-Henseleit buffer ( $\mathrm{pH}$ 7.4) by the repetition of the centrifugation at $50 \times \mathrm{g}$ for $3 \mathrm{~min}$, and then resuspended in ice-cold Krebs-Henseleit buffer containing 3\% bovine serum albumin, penicillin-G (K-salt, $0.2 \mathrm{mg} /$ $\mathrm{ml})$ and streptomycin $(0.2 \mathrm{mg} / \mathrm{ml})$. These hepatocytes had a viability of more than $90 \%$ as estimated by the trypan blue exclusion test. For maintaining hepatocytes as a monolayer in primary culture, the procedure described by Bonney et al. (11) was used. The freshly isolated and washed hepatocytes were suspended in Eagle's minimal essential medium [MEM. pH 7.4; supplemented with $10 \%$ fetal calf serum, $10 \mathrm{mM} \mathrm{N}$-Tris (hydroxymethyl)-methyl-2-amino ethanesulfonic acid (TES), $10 \mathrm{mM} \mathrm{N}$-2-hydroxyethylpiperazine$\mathrm{N}$-ethanesulfonic acid (HEPES), $10 \mu \mathrm{M}$ dexamethasone, insulin $(10 \mathrm{mU} / \mathrm{ml})$, carbenicillin $(0.1 \mathrm{mg} / \mathrm{ml})]$, and the cell number was adjusted to $1.0 \times 10^{6} \mathrm{cells} / \mathrm{ml}$ of suspension. Three $\mathrm{ml}$ of the suspension were added into each Corning plastic culture dish (60 $\mathrm{mm}$ in diameter) and placed in an incubator for maintaining at $37^{\circ} \mathrm{C}$ under humidified $5 \% \mathrm{CO}_{2}$ in air for $24 \mathrm{hr}$. The planting efficiency $24 \mathrm{hr}$ after the initiation of incubation was examined by the method of Morse and Potter (12) and was found to be approximately 60 percent.

For investigating the effect of insulin, 
glucagon and isoproterenol on the uptakes of taurine and AIB by hepatocytes in primary culture, the experiments were carried out as follows: MEM in a culture dish to which hepatocytes were attached was discarded by aspiration, and the culture dish was rinsed three times with $5 \mathrm{ml}$ of warm $\left(37^{\circ} \mathrm{C}\right)$ KrebsHenseleit buffer ( $\mathrm{pH} 7.4)$. This procedure was followed by the addition of $2 \mathrm{ml}$ of KrebsHenseleit buffer $\left(37^{\circ} \mathrm{C}, \mathrm{pH} 7.4\right)$ containing penicillin $\mathrm{G}(0.2 \mathrm{mg} / \mathrm{ml})$ and streptomycin $(0.2 \mathrm{mg} / \mathrm{ml})$ into the culture dish. The incubation was started following the simultaneous addition of insulin, glucagon or isoproterenol, and $100 \mu \mathrm{M}\left[{ }^{3} \mathrm{H}\right]$ taurine or $1 \mathrm{mM}\left[{ }^{14} \mathrm{C}\right] \mathrm{AlB}$, respectively. The incubation was carried out at $37^{\circ} \mathrm{C}$ in humidified $5 \%$ $\mathrm{CO}_{2}$ in air, and it was terminated by rapid aspiration of the Krebs-Henseleit buffer containing radio-labeled amino acids, followed by rinsing the culture dish five times with $3 \mathrm{ml}$ of ice-cold Krebs-Henseleit buffer within $45 \mathrm{sec}$. Two $\mathrm{ml}$ of $0.1 \mathrm{~N} \mathrm{NaOH}$ were added to the culture dish for the digestion of hepatocytes, and an aliquot of digested hepatocytes was transferred to a scintillation counting vial with $10 \mathrm{ml}$ of Triton toluene scintillator [Triton:toluene (containing $5 \mathrm{~g}$ PPO and $0.3 \mathrm{~g}$ POPOP per liter) $=1: 2]$ for the measurement of radioactivity accumulated in hepatocytes. An aliquot of hepatocytes dissolved in $0.1 \mathrm{~N}$ $\mathrm{NaOH}$ was also used for the measurement of protein content.

The amount of $\left[{ }^{3} \mathrm{H}\right]$ taurine-conjugated bile acids formed by primary cultured hepatocytes was determined $5 \mathrm{hr}$ after the incubation with $\left[{ }^{3} \mathrm{H}\right]$ taurine. The incubation was terminated by withdrawing the medium. The incubation medium was aspirated, and the aliquots of medium used for washings were combined and transferred to an another vessel, followed by the addition of methanolacetone $(1: 1, v / v)$. Hepatocytes were then scraped off by a rubber policeman and also mixed with methanol-acetone. The methanolacetone mixtures with hepatocytes and incubation medium were centrifuged respectively at $800 \times \mathrm{g}$ for $10 \mathrm{~min}$. After decanting the supernatant, each sediment was mixed with methanol-acetone and recentrifuged. The supernatants obtained by the first and second centrifugations were mixed and lyophilized at $80^{\circ} \mathrm{C}$ (13). The lyophilized samples prepared from hepatocytes and incubation medium were separately dissolved into methanol. After separating bile acids in each fraction from hepatocytes and incubation medium by thin layer chromatography (14). spots corresponding with authentic taurocholic acid and taurodihydroxybile acids were scraped off and transferred to vials containing $500 \mu \mathrm{l}$ methanol to extract the bile acids from the silica gel G. Finally, the radioactivities of $\left[{ }^{3} \mathrm{H}\right]$ taurine-conjugated bile acids in hepatocytes and incubation medium were measured respectively in a liquid scintillation spectrometer after the addition of Triton-toluene scintillator. The net amount of $\left[{ }^{3} \mathrm{H}\right]$ taurine-conjugated bile acids formed by primary cultured hepatocytes was calculated by summing the amount of $\left[{ }^{3} \mathrm{H}\right]$ taurine-conjugated bile acids detected in hepatocytes and that detected in the incubation medium. The recoveries of standard conjugated bile acids during thin layer chromatographic procedures were more that $85 \%$.

Protein contents in freshly isolated and primary cultured hepatocytes were determined by the method of Lowry et al. (15) using bovine serum albumin as a standard.

Insulin $\left(10^{-6} \mathrm{M}\right)$, glucagon $\left(10^{-6} \mathrm{M}\right)$ and isoproterenol $\left(10^{-4} \mathrm{M}\right)$ had no effect on the transport of taurine as well as that of AIB in freshly isolated hepatocytes during $1 \mathrm{hr}$ incubation. Similarly, no effect of these drugs was observed when the time of incubation was extended to $2 \mathrm{hr}$. Based on these results, it is suspected that freshly isolated hepatocytes used in this study may lose the responsiveness to hormones including insulin and glucagon, which agrees well with a previous report (16).

On the other hand, the transport of AIB in primary cultured hepatocytes was obviously facilitated by glucagon following $3 \mathrm{hr}$ incubation (Fig. 1A). The increase in the amount of AIB accumulated in hepatocytes was also observed $5 \mathrm{hr}$ after the initiation of incubation in the presence of insulin, glucagon and isoproterenol, although no effect of these drugs was noticed following $1 \mathrm{hr}$ incubation. These results clearly indicate 

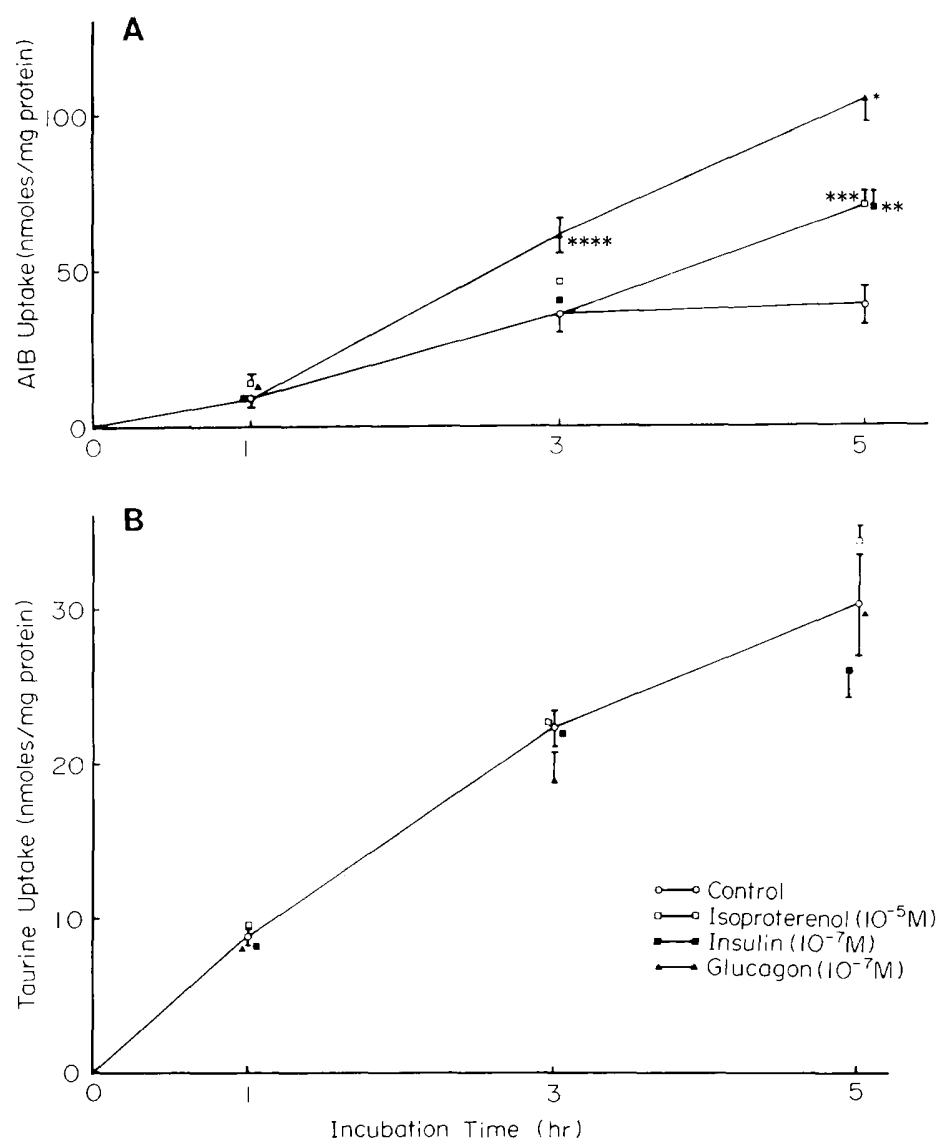

Fig. 1. Effect of isoproterenol, insulin and glucagon on uptakes of $\alpha$-aminoisobutyric acid (AIB: $A$ ) and taurine (B) by hepatocytes in primary culture. Hepatocytes were incubated with Krebs-Henseleit buffer containing $1 \mathrm{mM}\left[{ }^{14} \mathrm{C}\right] \mathrm{AlB}$ or $100 \mu \mathrm{M}\left[{ }^{3} \mathrm{H}\right]$ taurine up to $5 \mathrm{hr}$ in the presence and absence of various drugs. Each value represerits the mean \pm S.E.M. obtained from four to eight dishes. ${ }^{*} P<0.001,{ }^{*} P<0.01$, ${ }^{* * *} \mathrm{P}<0.02,{ }^{* * *} \mathrm{P}<0.05$, compared with each control value.

that freshly isolated hepatocytes have no responsiveness to various hormones, but these hormonal sensitivities are recovered, at least in part, following the primary culture of these cells for $24 \mathrm{hr}$. These findings essentially agree with previous reports (17-19).

In contrast to a remarkable increase in the accumulation of AIB in primary cultured hepatocytes by these hormones, no induction of the increase in taurine transport was noted under the same experimental conditions (Fig. 1B). The results clearly indicate that hepatocellular transport of taurine is not modulated by these hormones and is distinct from that of AlB in terms of hormonal sensitivity.
The amount of $\left[{ }^{3} \mathrm{H}\right]$ taurine-conjugated bile acids formed in primary cultured hepatocytes in the absence or presence of insulin, glucagon and isoproterenol is shown in Table 1. One-tenth $\mu \mathrm{M}$ of insulin, which induced a significant increase in AIB accumulation, significantly facilitated the formation of $\left[{ }^{3} \mathrm{H}\right]$ taurine-conjugated bile acids by primary cultured hepatocytes. In contrast, $10^{-5}-10^{-7} \mathrm{M}$ glucagon and isoproterenol, which exhibited a significant accentuating effect on AlB transport, had no effect on the formation of $\left[{ }^{3} \mathrm{H}\right]$ taurine-conjugated bile acids in these cells. These results indicate that insulin, but not glucagon and isoproterenol, facilitates the formation of 
Table 1. Effect of isoproterenol, insulin and glucagon on the formation of $\left[{ }^{3} \mathrm{H}\right]$ taurine-conjugated bile acids by hepatocytes in primary culture

\begin{tabular}{lc}
\hline & $\begin{array}{c}{\left[{ }^{3} \mathrm{H}\right] \text { taurine-conjugated bile acids formed }} \\
\text { (nmoles/mg prot. } \pm \text { S.E.M.) }\end{array}$ \\
Control & $12.85 \pm 0.73$ \\
Isoprotereriol $\left(10^{-5} \mathrm{M}\right)$ & $13.28 \pm 1.01$ \\
Insulin $\left(10^{-7} \mathrm{M}\right)$ & $17.97 \pm 1.24^{*}$ \\
Glucagon $\left(10^{-7} \mathrm{M}\right)$ & $13.28 \pm 0.72$ \\
\hline
\end{tabular}

Hepatocytes were iricubated with Krebs-Henseleit buffer containing $100 \mu \mathrm{M}\left[{ }^{3} \mathrm{H}\right]$ taurine in the presence of isoproterenol, insulin and glucagon for $5 \mathrm{hr}$. Each value represents the sum of taurine-conjugated bile acids detected in both hepatocytes and incubation medium. The mean \pm S.E.M. obtained from four separate experiments is presented. ${ }^{*} P<0.05$, compared with the control value.

taurine-conjugated bile acids.

It has been previously reported that AIB transport in primary cultured hepatocytes is facilitated by insulin, glucagon and isoproterenol (17-19). Similar results in regard to the hormonal sensitivity of AIB transport in hepatocytes maintained in primary culture have been observed in this study. These results indicate that primary cultured hepatocytes undoubtedly possess the capacity to respond to hormones, although these cells have no sensitivity to hormones immediately after the isolation. This rapid restoration of hepatocellular hormonal sensitivity due to primary culture for $24 \mathrm{hr}$ is in sharp contrast to the fact that primary culture induces the deterioration of metabolic activities such as the metabolism of carbohydrate (20) and various drugs (21) in hepatocytes.

With regard to the effect of insulin, glucagon and isoproterenol on the taurine transport in primary cultured hepatocytes, no apparent alteration in taurine transport was detected as shown in Fig. 1. Since it has been well established that taurine transported into hepatocytes is conjugated with bile acids (22, 23), and taurocholic acid, one of the major taurine-conjugated bile acids in rats, is rapidly secreted into medium by isolated hepatocytes (24-26), we have examined the formation of $\left[{ }^{3} \mathrm{H}\right]$ taurine-conjugated bile acids in primary cultured hepatocytes in the presence and absence of insulin, glucagon and isoproterenol. The experimental results clearly demonstrated that insulin increased the formation of $\left[{ }^{3} \mathrm{H}\right]$ taurine-conjugated bile acids by primary cultured hepatocytes, but glucagon and isoproterenol had no such stimulatory effects on the formation of $\left[{ }^{3} \mathrm{H}\right]$ taurine-conjugated bile acids.

The metabolic steps by which taurine is conjugated with bile acids consist of two enzymatic reactions $(4,27)$. The first reaction is the formation of bile acid-Co A complex mediated by cholyl-Co A synthetase (EC $6: 2.1 .7)$. The reaction of bile acid-Co $A$ complex with taurine is successively catalyzed by bile acid-Co $\mathrm{A}$ : amino acid $\mathrm{N}$-acyltransferase (EC 2.3.1) and forms taurineconjugated bile acid. Since it is well known that insulin facilitates not only protein synthesis but also the synthesis of various enzymes, it is probable that this hormone accelerates the biosynthesis of these enzymes involved in the biosynthetic pathway of taurine-conjugated bile acids. Although exact molecular mechanisms underlying the facilitating effect of insulin on the hepatocellular formation of taurine-conjugated bile acids remain to be elucidated, present results clearly indicate that this facilitation is not due to the increased transport of taurine in these cells.

\section{References}

1 Guidotti, G.G., Borghetti, A.F. and Gazzola, G.C.: The regulation of amino acid transport in animal cells. Biochim. Biophys. Acta 515, 329_ 366 (1978)

2 Shotwell, M.A., Kilberg, M.S. and Oxender, D.L.: The regulation of neutral amino acid transport in mammalian cells. Biochim. Biophys. Acta 737, 267-284 (1983)

3 Jacobsen, J.G. and Smith, L.H., Jr.: Biochemistry and physiology of taurine and taurine derivatives. Physiol. Rev. 48, 424-511 (1968) 
4 Bremer, J.: Cholyl-S-Co A as an intermediate in the conjugation of cholic acid with taurine by rat liver microsomes. Acta Chem. Scand. 10, 56-71 (1956)

5 Killenberg, P.G. and Jordan, J.T.: Purification and characterization of bile acids-Co A: Amino acid $\mathrm{N}$-acyltransferase from rat liver. J. Biol. Chem. 253, 1005-1010 (1978)

6 Vessey, D.A.: The biochemical basis for the conjugation of bile acids with either glycine or taurine. Biochem. J. 174, 621-626 (1978)

7 Ohkuma, S., Tamura, J., Kuriyama, K. and Takino, T.: Characteristics of taurine transport in freshly isolated rat hepatocytes. Japan. J. Pharmacol. 31, 1061-1070 (1981)

8 Hardison, W.G.M. and Weiner, R.: Taurine transport by rat hepatocytes in primary culture. Biochim. Biophys. Acta 598, 145-152 (1980)

9 Ohkuma, S., Tamura, J., Kuriyama, K. and Mukainaka, T.: Characteristics of taurine transport in rat hepatocytes in primary culture. Cell Biochemistry and Function (iri press)

10 Berry, M.N. and Friend, D.S.: High-yield preparation of isolated rat liver parenchymal cells. A biochemical and fine structural study. J. Cell Biol. 43, 506-520 (1969)

11 Bonney, R.J., Becker, J.E., Walker, P.R. and Potter, V.R.: Primary monolayer cultures of adult rat liver parenchymal cells suitable for study of the regulation of enzyme synthesis. In Vitro 9, 399-413 (1974)

12 Morse, P.A. and Potter, V.R.: Pyrimidine metabolism in tissue culture cells derived from rat hepatocytes. I. Suspension cell cultures derived from the Novikoff hepatoma. Cancer Res. 25, 499-508 (1965)

13 Bruusgaard, A.: Quantitative determination of the major 3-hydroxy bile acids in biological material after thin-layer chromatographic separation. Clin. Chem. Acta 28, 495-504 (1970)

14 Hoffman, A.F.: Thin layer adsorption chromatography for free and conjugated bile acids on silicic acid. J. Lipid Res. 3, 127-128 (1962)

15 Lowry, O.H., Rosebrough, N.J., Farr, A.L. and Randall, R.J.: Protein measurement with the Folin phenol reagent. J. Biol. Chem. 193, 265275 (1951)

16 Tanaka, K., Sato, M., Tomita, Y. and Ichihara, A.: Biochemical studies on liver functions in primary cultured hepatocytes of adult rats. I. Hormonal effect on cell viability and protein synthesis. J. Biochem. 84, 937-956 (1978)

17 Kletzien, R.F., Pariza, M.W., Becker, J.E., Potter, V.R. and Butcher, F.R.: Induction of amino acid transport in primary cultures of adult rat liver parenchymal cells by insulin. J. Biol. Chem. 251, 3014-3020 (1976)

18 Pariza, M.W., Bucher, F.R., Kletzien, R.F., Becker, J.E. and Potter, V.R.: Induction and decay of glucagon-induced amino acid transport in primary cultures of adult rat liver cells: Paradoxical effects of cycloheximide and puromycin. Proc. Natl. Acad. Sci. U.S.A. 73, $4511-$ 4515 (1976)

19 Pariza, M.W., Butcher, F.R., Becker, J.E. and Potter, V.R.: $3^{\prime}: 5^{\prime}$-Cyclic AMP: Independent induction of amino acid transport by epinephrine in primary cultures of adult rat liver cells. Proc. Natl. Acad. Sci. U.S.A. 74, 234-237 (1977)

20 Walker, P.R. and Grindle, M.J.: Effects of hormones and serum on glycogen metabolism in adult rat liver parenchymal cell primary cultures. J. Cell. Physiol. 91, 181-192 (1977)

21 Guzelian, P.S., Bissell, D.M. and Meyer, U.A.: Drug metabolism in adult rat hepatocytes in primary monolayer culture. Gastroenterology 72 , 1232-1239 (1977)

22 Portmann, O.W. and Mann, G.V.: The disposition of taurine- $S^{35}$ and taurocholate- $S^{35}$ in the rat: Dietary influences. J. Biol. Chem. 213, 733-743 (1955)

23 Sjövall, J.: Dietary glycine and taurine on bile acid conjugation in man. Bile acids and steroids 75. Proc. Soc. Exp. Biol. Med. 100, 676-678 (1959)

24 Anwer, M.S., Kroker, R. and Hegner, D.: Bile acids secretion and synthesis by isolated rat hepatocytes. Biochem. Biophys. Res. Commun. 64, 603-609 (1975)

25 Schwarz, L.R., Schwenk, M., Pfaff, E. and Greim, $\mathrm{H}$.: Excretion of taurocholate from isolated hepatocytes. Eur. J. Biochem. 71, 369-373 (1976)

26 Yousef, I.M., Ho, J. and Jeejeebhoy, K.N.: Bile acid synthesis in isolated rat hepatocytes. Can. J. Biochem. 56, 780-783 (1978)

27 Siperstein, M.D. and Murray, A.W.: Enzymatic synthesis of cholyl Co $A$ and taurocholic acid. Science 123, 377-378 (1955) 